\title{
Purification and Crystal Growth of the Bismuth (III) Iodide-influence of Trace Impurities on the Crystal Quality
}

\author{
Cauê de M. Ferraz ${ }^{1}$, Maria José A. Armelin ${ }^{1}$, Rene R. Oliveira ${ }^{1}$, Larissa Otubo ${ }^{1}$, João F. T. Martins ${ }^{1}$, Robinson A. dos \\ Santos $^{1}$, Fabio E. Costa ${ }^{1}$, Diego. V. S. Carvalho ${ }^{1}$, Nelson M. Omi ${ }^{1}$, C. H. Mesquita ${ }^{1}$, Margarida M. Hamada ${ }^{1}$ \\ ${ }^{1}$ Institute for Energetic and Nuclear Research - IPEN/CNEN - SP, São Paulo, Brazil \\ Correspondence: Margarida Mizue Hamada, Instituto de Pesquisas Energéticas e Nucleares-IPEN/CNEN-SP, Av. Prof. \\ Lineu Prestes, 2242, 05508-000 São Paulo, Brazil.
}

Received: July 4, 2017 Accepted: July 25, 2017 Online Published: July 31, 2017

doi:10.11114/set.v4i1.2566

URL: https://doi.org/10.11114/set.v4i1.2566

\begin{abstract}
This work describes the experimental procedure of purification and preparation of $\mathrm{BiI}_{3}$ crystals by Repeated Vertical Bridgman technique, aiming a future application of this semiconductor crystal as a room temperature radiation detector. The $\mathrm{BiI}_{3}$ powder used as raw material was purified three times and, at each purification, the crystal was evaluated by systematic measurements of the reduction of the impurities, crystalline structure, stoichiometry and surface morphology. The reduction of the trace metal impurities in the $\mathrm{BiI}_{3}$, at each purification, was analyzed by Instrumental Neutron Activation Analysis (INAA), in order to evaluate the efficiency of the purification technique established in this work. It was demonstrated that the Repeated Bridgman technique is effective to reduce the concentration of many impurities in $\mathrm{BiI}_{3}$, such as $\mathrm{Ag}, \mathrm{As}, \mathrm{Br}, \mathrm{Cr}, \mathrm{K}, \mathrm{Mo}, \mathrm{Na}$ and $\mathrm{Sb}$. The crystalline structure of the $\mathrm{BiI}_{3}$ crystal purified twice and three times was similar to $\mathrm{BiI}_{3}$ pattern. However, for $\mathrm{BiI}_{3}$ powder and purified once, an intensity contribution of the $\mathrm{BiOI}$ was observed in the diffractograms. Improvement in the stoichiometric ratio was observed at each purification step, as well as the crystal surface morphology.
\end{abstract}

Keywords: bismuth (III) iodide, crystal growth, semiconductor crystal, INAA

\section{Introduction}

A great interest has being focused on the development of the room temperature radiation detector, using semiconductor materials that have high atomic number and wide band gap. This type of detector has a large applicability as X ray and gamma ray spectrometer, operating at room temperature (McGregor \& Hermon, 1997; Martins et al, 2012; Oliveira et al, 2004). Layered semiconductor materials have a number of properties that make them attractive for such application. However, the common factor among the semiconductor materials to operate as room temperature semiconductor radiation detectors is their difficulty to obtain crystals with high purity, high crystallographic perfection and good chemical stoichiometry. It is know that the role of the impurities is crucial to grow crystals with these required characteristics, thus, improvements on the chemical purification and the impurity reduction analysis should be achieved (Martins et al, 2012; Oliveira et al, 2004).

Several studies are found in the literature on high-Z compound semiconductors, such as CdTe, Cd1-xZnxTe (CzT), $\mathrm{HgI}_{2}$, $\mathrm{PbI}_{2}$ and $\mathrm{TlBr}$ have been investigated as materials for nuclear radiation detectors that can operate at room temperature, since the early 80s (Martins et al, 2012; Oliveira et al, 2004; Oliveira et al, 2002; Hitomi \&Matsumoto, 2002).

Even though several studies on the preparation of room temperature semiconductor detectors and improvements in the methodology of purification, growth and characterization of the crystals have been carried out (Martins et al, 2012; Oliveira et al, 2004; Oliveira et al, 2002; Hitomi \&Matsumoto, 2002;Matsumoto et al, 2002; Qiu, 2010, Gokhale et al. 2014, Garg et al, 2014; Gokhalea et al, 2015; Santos et al. 2012), problems found in the room temperature semiconductor detectors are not yet completely resolved. Among them, the low collection efficiency of charge carriers and their stability, which are probably caused by impurities or defects created during the crystal growth. The semiconductor crystal purity is a crucial factor for its optimal performance as a radiation detector (Martins et al, 2012; Oliveira et al, 2004; Oliveira et al, 2002; Hitomi \&Matsumoto, 2002; Matsumoto et al, 2002; Qiu, 2010, Gokhalea et al. 2014).

More recently, $\mathrm{BiI}_{3}$ has emerged as a particularly interesting material well suited for use as $\mathrm{X}$ ray and $\gamma$ ray spectrometers at room temperature, in view of its wide band gap $(1.67 \mathrm{eV})$, large density $\left(5.7 \mathrm{~g} / \mathrm{cm}^{3}\right)$, high atomic 
number elements $\left(Z_{\mathrm{Bi}}=83, \mathrm{Z}_{\mathrm{I}}=53\right)$ and high resistivity $(>109 \Omega \mathrm{cm})$ (Matsumoto et al, 2002; Gokhalea et al. 2014). However the behavior of semiconductor devices is strongly influenced by the presence of impurities or contaminants remaining due to incomplete purification of the semiconductor material (Matsumoto et al, 2002). Small quantities of impurities present at concentrations below $1 \mathrm{ppb}$ can have a significant effect on quality of semiconductor devices. Nevertheless, as far as we know, few studies on impurities reduction methodology in $\mathrm{BiI}_{3}$ semiconductor crystals have been found in the literature.

In this paper, $\mathrm{BiI}_{3}$ crystals have been grown by the vertical Bridgman technique (Pfann, 1958) using commercially available powder. Efforts have been concentrated on the purification of the $\mathrm{BiI}_{3}$ and, the purification efficiency was assessed by analyzing the crystals, through instrumental neutron activation analysis (INAA). The analyzed crystals came from the impurity reduction process occurred after each purification by the Repeated Vertical Bridgman method. INAA is the elemental analysis method usually chosen for these projects because of some features such as: small amount of sample available, minimal sample handling and high sensitivity for many elements (Alfassi, 1998; Hamada, 2003). Also, the stoichiometry, the crystalline structure and the surface morphology were evaluated for each crystal grown by Vertical Bridgman methodology, as a function of purification number.

\section{Methodology}

Commercially available $\mathrm{BiI}_{3}$ powder (Alfa Aesar, A Johnson Matthey Company), with nominal purity of 99.99\%, was used as the starting material for growths of the $\mathrm{BiI}_{3}$ semiconductor crystals. $\mathrm{BiI}_{3}$ crystals were grown by the vertical Bridgman technique, using borosilicate glass tubes as crucibles in vacuum atmosphere. Preliminary, the tubes were submitted to a chemical treatment. The $2.0 \mathrm{~mm}$ diameter $\mathrm{x} 150 \mathrm{~mm}$ long borosilicate glass tubes were previously washed with a cleaning agent solution (Extran MA 02, Merck) for removal of possible dust particles and plumb. Afterward, the tubes were washed repeatedly with distilled water and, then, filled with a $30 \% \mathrm{NH}_{3}$ solution; after 10 minutes, the tubes were rinsed three times with demineralized water. Subsequently, the tubes were submitted to a thermal treatment at $530{ }^{\circ} \mathrm{C}$ to avoid the adhesion of the crystals on the walls of the tubes. Subsequently, $15 \mathrm{~g}$ of $\mathrm{BiI}_{3}$ powder was introduced into the treated tube, evacuated to 10-5 Torr and sealed off. The tube containing $\mathrm{BiI}_{3}$ powder was mounted into the vertical Bridgman furnace (Fig. $1 \mathrm{~A}$ ) and $\mathrm{BiI}_{3}$ was melted at a temperature of $530^{\circ} \mathrm{C}$; afterwards, the tube with $\mathrm{BiI}_{3}$ was moved vertically with a rate of $2 \mathrm{~mm} / \mathrm{hr}$ into the furnace. Fig. 1(B) shows the characteristic curve of the furnace temperature profile obtained for $\mathrm{BiI}_{3}$ crystal growth, by Bridgman method. This procedure was necessary to verify the symmetry of the temperature gradient before and after the maximum furnace temperature region.

Crystal around $2.0 \mathrm{~mm}$ diameter $\times 40 \mathrm{~mm}$ long was obtained, after each purification step. For each re-growth, the tube was opened in the clean room and the crystal was cleaved in the following dimensions: the "TOP" sample (upper region) with $\sim 3 \mathrm{~mm}$ thick, the "MIDDLE" sample with $\sim 23 \mathrm{~mm}$ thick and the "BOTTOM" with $\sim 13 \mathrm{~mm}$ thick, as shown in Figure 2. Samples from each crystal region were taken for performing the physical-chemical characterizations, after each purification step. After taking a small piece from the MIDDLE region, this was used for new purification. Following the same procedure, the crystals were grown repeatedly (three times) for purification, since the impurities tend to migrate to the extremities of the crystal, during the growth, due to the impurities segregation along the crystal. 


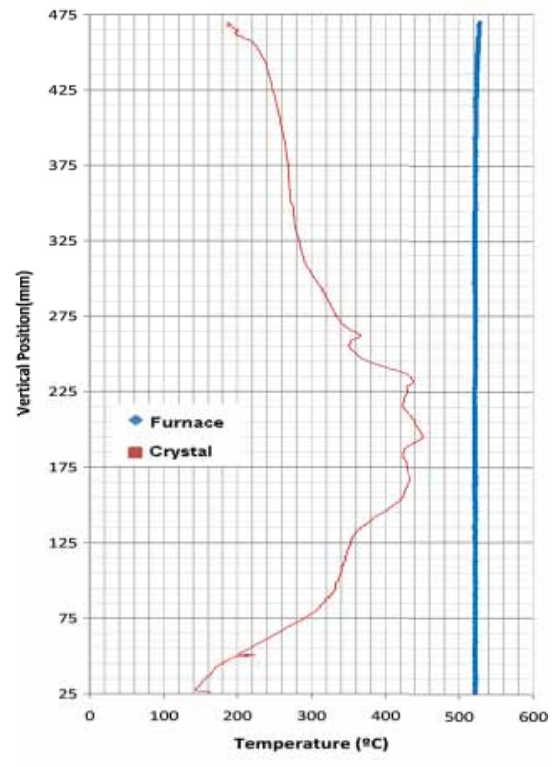

(A)

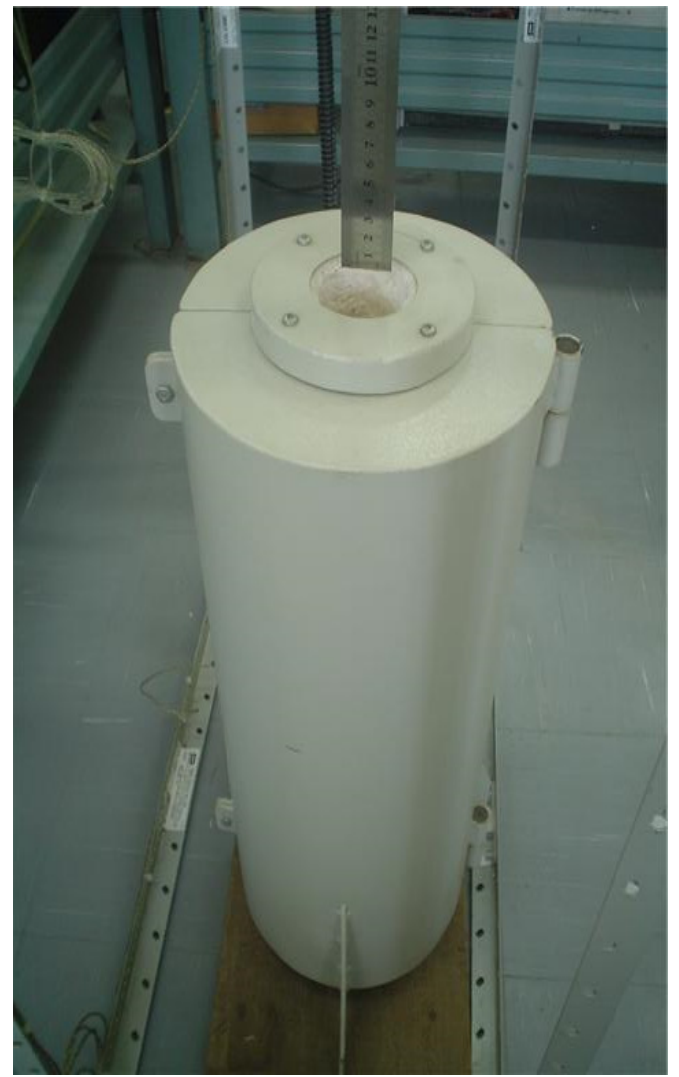

(B)

Figure 1. Typical curve of furnace temperature: redline crystal growth temperature and blue line furnace temperature (A) and Vertical Bridgman Furnace used for $\mathrm{BiI}_{3}$ purification (B)

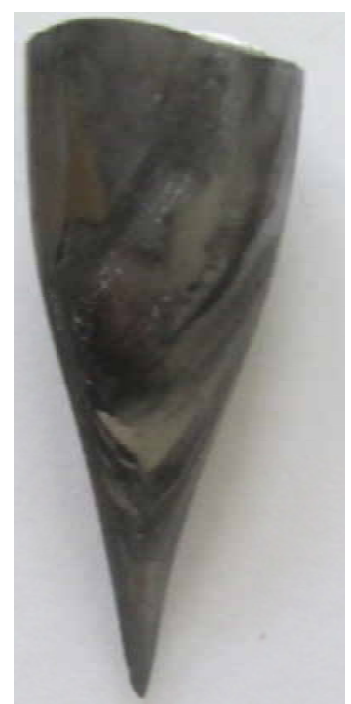

(A)

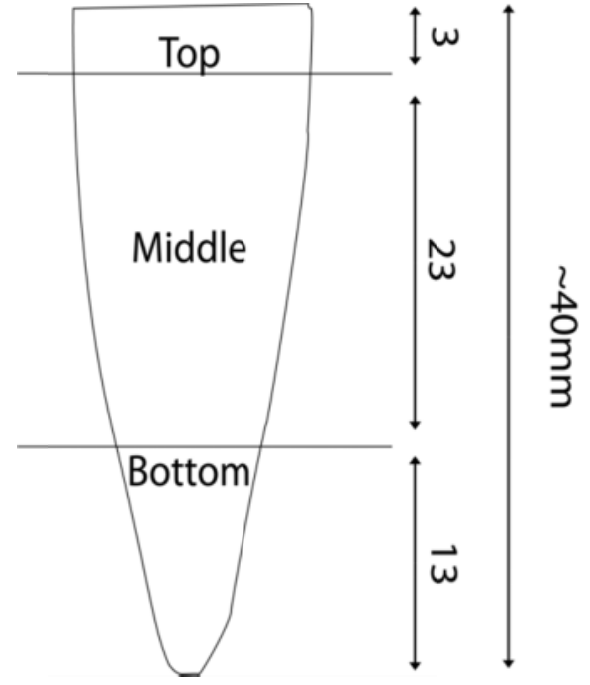

(B)

Figure 2. Crystal obtained by Repeated Bridgman purification (A); Crystal dimensions and cleavage proportions (B) 
A small amount of about $150 \mathrm{mg}$ of sample was taken from each slice (samples TOP, MIDDLE and BOTTON) to identify and determine the concentration of impurities. The impurity concentrations of the samples, taken from slices after each growth and $\mathrm{BiI}_{3}$ powder were analyzed by the Instrumental Neutron Activation Analysis (INAA) technique (Oliveira, 2002). For this, $\mathrm{BiI}_{3}$ aliquots ranging from 40 to $120 \mathrm{mg}$ were transferred to polyethylene bags, which had been cleaned by leaching with a diluted $\mathrm{HNO}_{3}(1: 5)$ and purified water. Certified standard solutions (Spex Certiprep) of $\mathrm{Ag}, \mathrm{As}, \mathrm{Br}, \mathrm{Cr}, \mathrm{K}, \mathrm{Mo}, \mathrm{Na}, \mathrm{Sb}$ and $\mathrm{Zn}$ were used to prepare the standards. Aliquots (50-100 $\mu \mathrm{L}$ ) of these solutions were transferred to small sheets of analytical filter paper (Whatman number 42). After drying, these filter papers were placed into polyethylene bags for irradiation. Irradiations were carried out at the IEA-R1 nuclear research reactor of IPEN-CNEN/SP. The thermal neutron flux utilized ranged from 0.1 to $1,2 \times 10^{12} \mathrm{n} \mathrm{cm}^{-2} \mathrm{~s}^{-1}$. Samples and standards (Ag, $\mathrm{As}, \mathrm{Br}, \mathrm{Cr}, \mathrm{K}, \mathrm{Mo}, \mathrm{Na}$ and $\mathrm{Sb}$ ) were irradiated simultaneously in an aluminum container for $7 \mathrm{~h}$. The ${ }^{76} \mathrm{As},{ }^{82} \mathrm{Br},{ }^{42} \mathrm{~K}$, ${ }^{99} \mathrm{Mo}$, ${ }^{24} \mathrm{Na}$ and ${ }^{122} \mathrm{Sb}$ activities were measured after 3 days of decay time, while ${ }^{110 \mathrm{~m}} \mathrm{Ag}$ and ${ }^{51} \mathrm{Cr}$ were measured after, at least, 8 days of decay time. In addition, analyses of certified reference material NIST 2710 Montana Soil was also carried out simultaneously to take control of the analysis process. The equipment used to measure the gamma-radiation was a model GX2020 hyperpure Ge detector, coupled to a model 1510 Integrated Signal Processor and MCA System 100 , both from Canberra. The detector used had a resolution (FWHM) of $0.9 \mathrm{keV}$ for $122 \mathrm{keV}$ gamma rays of ${ }^{57} \mathrm{Co}$ and $1.9 \mathrm{keV}$ for $1332 \mathrm{keV}$ gamma-ray of ${ }^{60} \mathrm{Co}$.

The crystalline quality was analyzed by X-ray diffraction (DRX) (Keller, 1996) for samples from the regions (Top, Middle, Bottom) at each growth process. An X-ray diffractometer Phillips Model DR 714020 with $\mathrm{Cu} \mathrm{K} \alpha$ radiation target $\left(40 \mathrm{kV}, 35 \mathrm{~mA}\right.$, in the $2 \theta$ range from 0 to $\left.60^{\circ}\right)$ was used for structural characterization of $\mathrm{BiI}_{3}$ crystal grown with different impurities.

Scanning electron microscopy analyses were performed to verify the morphology and elemental chemical composition of the $\mathrm{BiI}_{3}$ crystals at different levels of purification, as well as to investigate the surface quality in the Top, Middle and Bottom regions from the crystals purified once, twice and three times. This method allows observing the surface homogeneity and structural quality on a much larger scale (10-20,000 X). Both, analyses the surface morphology and the stoichiometry $\mathrm{BiI}_{3}$ crystals were evaluated by SEM-BSE technique, using a scanning electron microscope LX 30 , from Philips. For these experiments, $0.50 \mathrm{~mm}$ slices were cleaved from the three regions at each growth.

\section{Results and Discussion}

Figure 3 shows a typical crystal of $\mathrm{BiI}_{3}$ obtained by the Bridgman technique before and after purification. The crystals obtained in the first growth showed a blackish gray coloration. A better crystal quality was observed in the crystals with higher purity. These crystals had fewer imperfections and high translucency and uniformity. No significance difference was observed in the crystal visual aspects between two and three purifications.

$$
\text { Before (A) }
$$

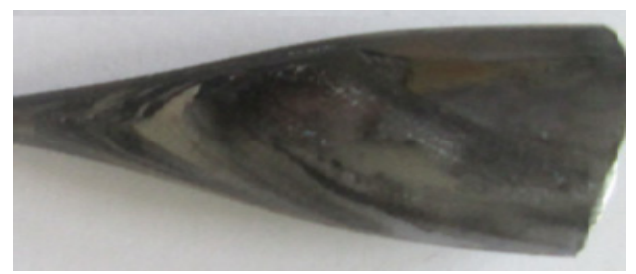

After (B)

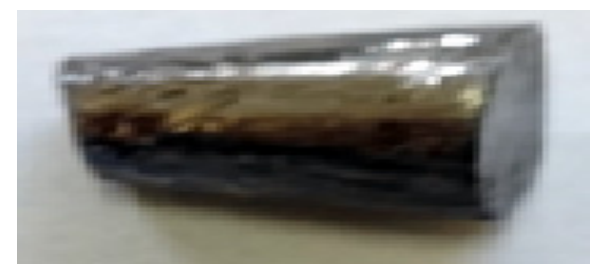

Figure 3. Pictures of the $\mathrm{BiI}_{3}$ crystals without (A) and after three purifications (B)

To assess the effectiveness of the Repeated Bridgman methodology as a means of purification, the INAA technique was employed to investigate the presence and concentrations of impurities in three different regions (top, middle and bottom) of the crystal in function of purification number and in the commercial $\mathrm{BiI}_{3}$ powder. The following impurities were identified: $\mathrm{Ag}, \mathrm{As}, \mathrm{Br}, \mathrm{Cr}, \mathrm{K}, \mathrm{Mo}, \mathrm{Na}$ and $\mathrm{Sb}$ in the $\mathrm{BiI}_{3}$ crystals. It is important to stand out that the reduction of the impurities present in the $\mathrm{BiI}_{3}$, after purification by Repeated Bridgman technique, is being reported by the first time in this work.

In order to evaluate the performance of INAA for the determination of impurities in $\mathrm{BiI}_{3}$ is important to take into consideration certain nuclear characteristics of the radionuclides formed by the reaction $(\mathrm{n}, \mathrm{\gamma}$ ) on the matrix (Table 1). As can be seen, the probability of formation of bismuth radionuclides is very small. For this reason, bismuth does not prevent the application of INAA in this study. However, the reaction of formation of the ${ }^{128} \mathrm{I}$ is very effective $(\sigma=6200$ Millibarns). It is a produced radionuclide $\left(\mathrm{T}_{1 / 2}=24.9\right.$ minutes) making it impossible to determine impurities whose reaction $(\mathrm{n}, \mathrm{y})$ form radionuclides whose half-lives are of the order minutes or few hours, such as ${ }^{66} \mathrm{Cu},{ }^{52} \mathrm{~V},{ }^{51} \mathrm{Ti},{ }^{56} \mathrm{Mn}$. 


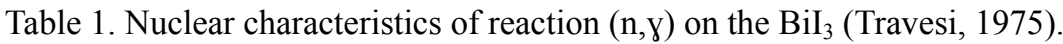

\begin{tabular}{cccccc}
\hline \multicolumn{5}{c}{ Parameters } \\
\hline Stable isotope & $\begin{array}{c}\text { Isotopic } \\
\text { abundance }\end{array}$ & $\begin{array}{c}\text { Nuclear } \\
\text { reaction }\end{array}$ & Cross section & $\begin{array}{c}\text { Isotope } \\
\text { produced }\end{array}$ & Half - life \\
- & $\mathbf{\%}$ & - & Millibarns & - & Y, D or M* $^{*}$ \\
${ }^{209} \mathrm{Bi}$ & 100.00 & $(\mathrm{n}, \mathrm{\gamma})$ & 15.0 & ${ }^{210 \mathrm{~m}} \mathrm{Bi}$ & $0.3 \mathrm{E}+07 \mathrm{Y}$ \\
${ }^{209} \mathrm{Bi}$ & 100.00 & $(\mathrm{n}, \mathrm{\gamma})$ & 19.0 & ${ }^{210} \mathrm{Bi}$ & $5.01 \mathrm{D}$ \\
${ }^{127} \mathrm{I}$ & 100.00 & $(\mathrm{n}, \mathrm{\gamma})$ & 6200.0 & ${ }^{128} \mathrm{I}$ & $24.90 \mathrm{M}$ \\
\hline
\end{tabular}

* $\mathrm{Y}=$ year; $\mathrm{D}=$ day; $\mathrm{M}=$ minute

The results of the analysis of impurities in the samples obtained from the $\mathrm{BiI}_{3}$ purification carried out by Bridgman technique are shown in Table 2. Each result is the mean of two or three measures followed by the standard deviation.

The results obtained in the certified reference material NIST 2710 Montana Soil, used for quality control, showed good agreement with the certified values, for most of elements. In most cases, the accuracy of $\mathrm{BiI}_{3}$ analyzes (Table 2) were below 20\%. As such, the results showed that INAA can be a useful instrument to monitor impurities (Ag, As, Br, Cr, K, $\mathrm{Mo}, \mathrm{Na}$ and $\mathrm{Sb}$ ) in the various stages of the $\mathrm{BiI}_{3}$ purification methodology.

The efficiency assessment of the purification methodology based on the observed results (Table 2) depends on the knowledge of the segregation coefficients of the elements in the surroundings, which is beyond of the scope of the present study. However, it should be emphasized that INAA demonstrated to be a sensitive analytical technique useful to identify both qualitative and quantitative multi-element analysis of trace elements in $\mathrm{BiI}_{3}$ in order to distinguish the segregation of the impurities along the crystal, as shown in Table 2. It was observed a trend for impurities to segregate to the upper part of the ingot (last to freeze), as a consequence of their segregation during the growth process, suggesting that the segregation coefficient $(\mathrm{k})$ of this element is $\mathrm{k}>1$. It also appears that the most of impurity concentrations is smaller towards the middle of the ingot, indicating that for these elements the segregation coefficient is below or above unity. So, these impurities segregate to the first or last parts of the ingot to freeze (Oliveira, 2004, 2005).

The impurity concentration tendency of the middle region to decrease in function of the purification number of the $\mathrm{BiI}_{3}$ is illustrated in the Fig. 3. As it can be observed, there was a significant reduction of most impurities according to the purification numbers, excepting for Br. The decrease depends on each element, since they have different segregation coefficients. For a segregation coefficient very different from a unity, the Bridgman process was more efficient to remove the impurities to one of the tube ends. Mo was fully removed at the first purification, while, $\mathrm{As}, \mathrm{Cr}$ and $\mathrm{Sb}$ impurities decreased significantly after the third purification. Almost all impurities decreased, excepting Br, whose quantity, contrarily, increased after each purification number. Probably, the segregation coefficient is less than $1(\mathrm{k}<1)$ or some contamination may have occurred during the experiments. Further studies should be carried out to elucidate this result. It should be emphasized that there is few literature describing the impurities present in the starting material (powder) for $\mathrm{BiI}_{3}$ crystal growth and, even among these few references, there is no consensus among the elements found (Matsumoto et al, 2002; Qiu, 2010, Gokhale et al. 2014, Garg et al, 2014; Gokhalea et al, 2015). 
Table 2. Elemental concentrations (Mean \pm Standard deviation) determined in $\mathrm{BiI}_{3}$ crystals purified once, twice and third times, by INAA methods

\begin{tabular}{|c|c|c|c|}
\hline \multirow{2}{*}{$\begin{array}{c}\text { Element } \\
\text { Unit }\end{array}$} & \multicolumn{3}{|c|}{$1^{\text {st }}$ Purification } \\
\hline & Botton & Middle & Top \\
\hline $\mathrm{Ag}, \mu \mathrm{g} \mathrm{kg}^{-1}$ & $3519 \pm 389$ & $3450 \pm 331$ & $4312 \pm 436$ \\
\hline As, $\mu \mathrm{g} \mathrm{kg}^{-1}$ & $1996 \pm 153$ & $624 \pm 46$ & $3556 \pm 531$ \\
\hline $\mathrm{Br}, \mu \mathrm{g} \mathrm{kg}^{-1}$ & $872 \pm 91$ & $720 \pm 38$ & $679 \pm 61$ \\
\hline $\mathrm{Cr}, \mu \mathrm{g} \mathrm{kg}^{-1}$ & $1736 \pm 54$ & $1054 \pm 16$ & $6625 \pm 54$ \\
\hline $\mathrm{K}, \mathrm{mg} \mathrm{kg}^{-1}$ & $15 \pm 0,9$ & $12.5 \pm 0.4$ & $25 \pm 3,0$ \\
\hline $\mathrm{Mo}, \mu \mathrm{g} \mathrm{kg}^{-1}$ & $28 \pm 1,0$ & ND & $82 \pm 3,9$ \\
\hline $\mathrm{Na}, \mathrm{mg} \mathrm{kg}^{-1}$ & $13 \pm 0,8$ & $11 \pm 0.07$ & $22 \pm 1,1$ \\
\hline $\mathrm{Sb}, \mu \mathrm{g} \mathrm{kg}^{-1}$ & ND & $43 \pm 6$ & $75 \pm 3,9$ \\
\hline \multirow{2}{*}{$\begin{array}{c}\text { Element } \\
\text { Unit }\end{array}$} & \multicolumn{3}{|c|}{$2^{\text {nd }}$ Purification } \\
\hline & Botton & Middle & Top \\
\hline $\mathrm{Ag}, \mu \mathrm{g} \mathrm{kg}^{-1}$ & $3518 \pm 318$ & $3371 \pm 50$ & $4351 \pm 307$ \\
\hline As, $\mu \mathrm{g} \mathrm{kg}^{-1}$ & $425 \pm 82$ & $358 \pm 115$ & $759 \pm 20$ \\
\hline $\mathrm{Br}, \mu \mathrm{g} \mathrm{kg}^{-1}$ & $1255 \pm 268$ & $1109 \pm 178$ & $1074 \pm 8$ \\
\hline $\mathrm{Cr}, \mu \mathrm{g} \mathrm{kg}^{-1}$ & $1007 \pm 278$ & $752 \pm 186$ & $7615 \pm 705$ \\
\hline $\mathrm{K}, \mathrm{mg} \mathrm{kg}^{-1}$ & $11.9 \pm 0.1$ & $9.9 \pm 0.2$ & $19 \pm 2$ \\
\hline Mo, $\mu \mathrm{g} \mathrm{kg}^{-1}$ & $871 \pm 231$ & ND & $3026 \pm 278$ \\
\hline $\mathrm{Na}, \mathrm{mg} \mathrm{kg}^{-1}$ & $13.5 \pm 0.6$ & $12.3 \pm 0.1$ & $25.3 \pm 0.5$ \\
\hline $\mathrm{Sb}, \mu \mathrm{g} \mathrm{kg}^{-1}$ & $15 \pm 2$ & $9 \pm 1$ & ND \\
\hline \multirow{2}{*}{$\begin{array}{c}\text { Element } \\
\text { Unit }\end{array}$} & \multicolumn{3}{|c|}{$3^{\text {rd }}$ Purification } \\
\hline & Botton & Middle & Top \\
\hline $\mathrm{Ag}, \mu \mathrm{g} \mathrm{kg}^{-1}$ & $1879 \pm 102$ & $1651 \pm 86$ & $2851 \pm 1039$ \\
\hline As, $\mu \mathrm{g} \mathrm{kg}^{-1}$ & $50 \pm 4$ & $28 \pm 6$ & $716 \pm 34$ \\
\hline $\mathrm{Br}, \mu \mathrm{g} \mathrm{kg}^{-1}$ & $1281 \pm 33$ & $1145 \pm 3$ & $1184 \pm 181$ \\
\hline $\mathrm{Cr}, \mu \mathrm{g} \mathrm{kg}^{-1}$ & $557 \pm 124$ & $184 \pm 51$ & $9062 \pm 431$ \\
\hline $\mathrm{K}, \mathrm{mg} \mathrm{kg}^{-1}$ & $11 \pm 2$ & $9.4 \pm 0.5$ & $81 \pm 7$ \\
\hline Mo, $\mu \mathrm{g} \mathrm{kg}^{-1}$ & ND & ND & $7556 \pm 629$ \\
\hline $\mathrm{Na}, \mathrm{mg} \mathrm{kg}^{-1}$ & $19.8 \pm 0.6$ & $15.0 \pm 0.7$ & $516 \pm 23$ \\
\hline $\mathrm{Sb}, \mu \mathrm{g} \mathrm{kg}^{-1}$ & $6 \pm 1$ & $5.1 \pm 0.3$ & ND \\
\hline
\end{tabular}

$\mathrm{ND}$ - not detected

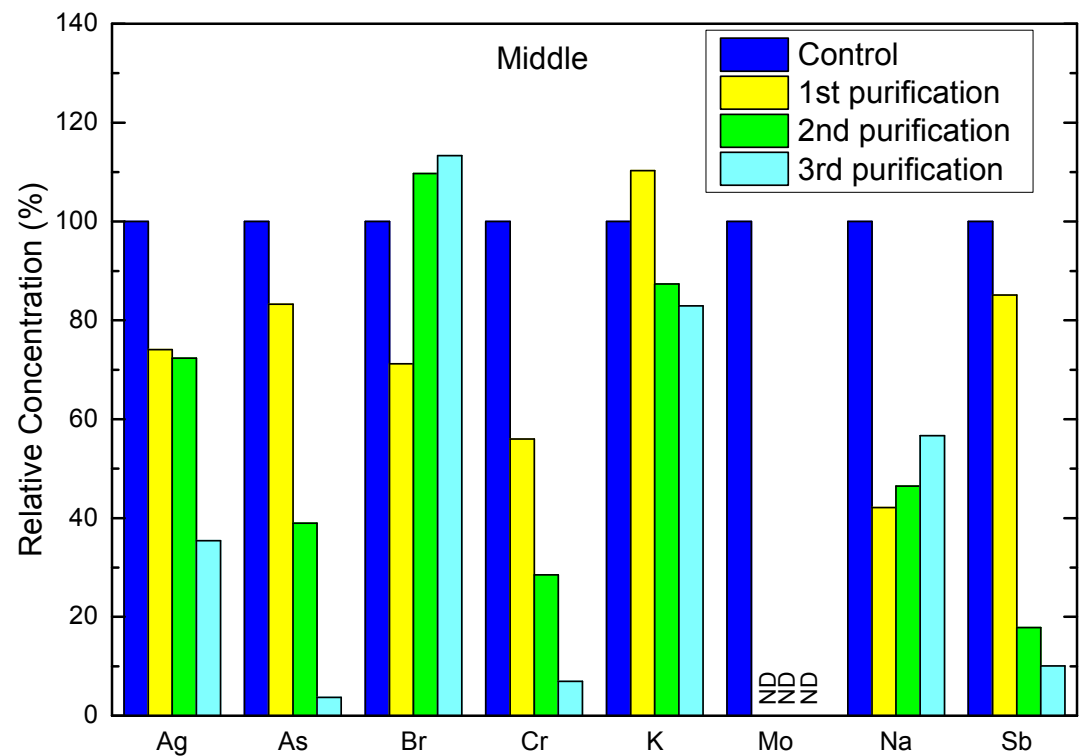

Figure 4. Impurity reduction of the concentration in function of the Bridgman purification number $\mathrm{ND}=$ no detected 
Fig. 4 and 5 present the X-ray diffraction characterization of samples from the bottom, middle and top regions of the crystal purified twice and three times, respectively, and the X-ray diffraction pattern of $\mathrm{BiI}_{3}$. As it can be observed from Fig. 4 and 5, crystals purified twice and three times present a similar structure with the rhombohedral crystalline pattern to $\mathrm{BiI}_{3}$ crystal (Matsumoto et al, 2002; Qiu, 2010). On the other hand, the diffractograms of $\mathrm{BiI}_{3}$ powder and the samples from crystal growth once (one purification) presented not only the peaks belonging to $\mathrm{BiI}_{3}$ crystals, but also, an intensive contribution from Bismuth Oxide Iodide (BiOI) appears at the angles, as it may be observed in Fig. 6 and 7. A background intensity contribution, which appears at the angles, probably due to some traces impurities, is still present in the crystal. However, the trace impurities did not affect, significantly, the crystalline structure, suggesting that the impurities did not enter in the crystal structure during the growth. Finally, it is worthwhile to observe that there were no other crystalline phases in the grown samples, above two times since all detected peaks were identified as belonging to $\mathrm{BiI}_{3}$. 


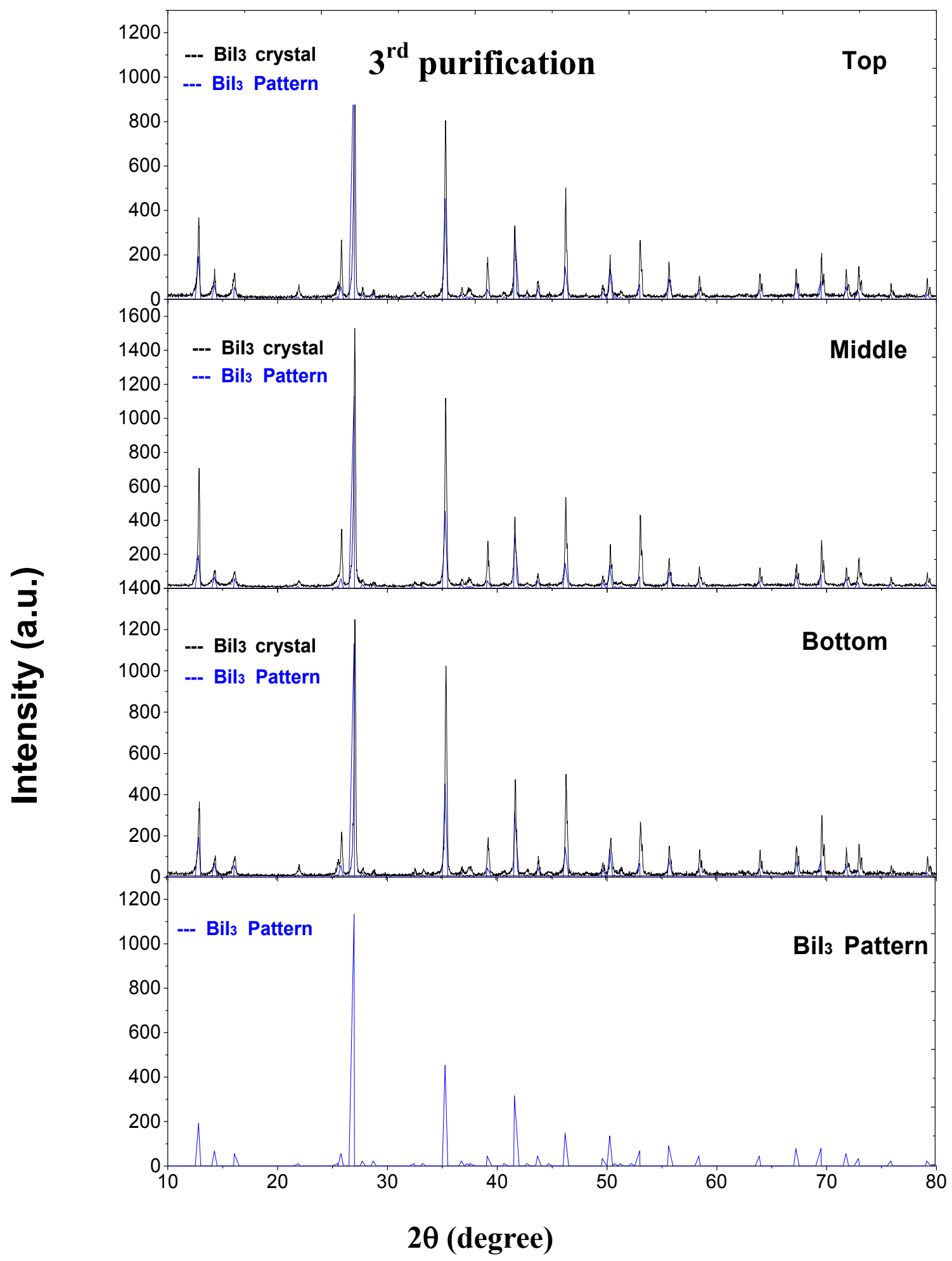

Figure 5. X-ray diffraction of the Top, Middle, Bottom samples from $\mathrm{BiI}_{3}$ crystal purified three times X-ray diffraction pattern of $\mathrm{BiI}_{3}$ (Card Information PDF Number: 48-1795) (Sillen, 1941). 


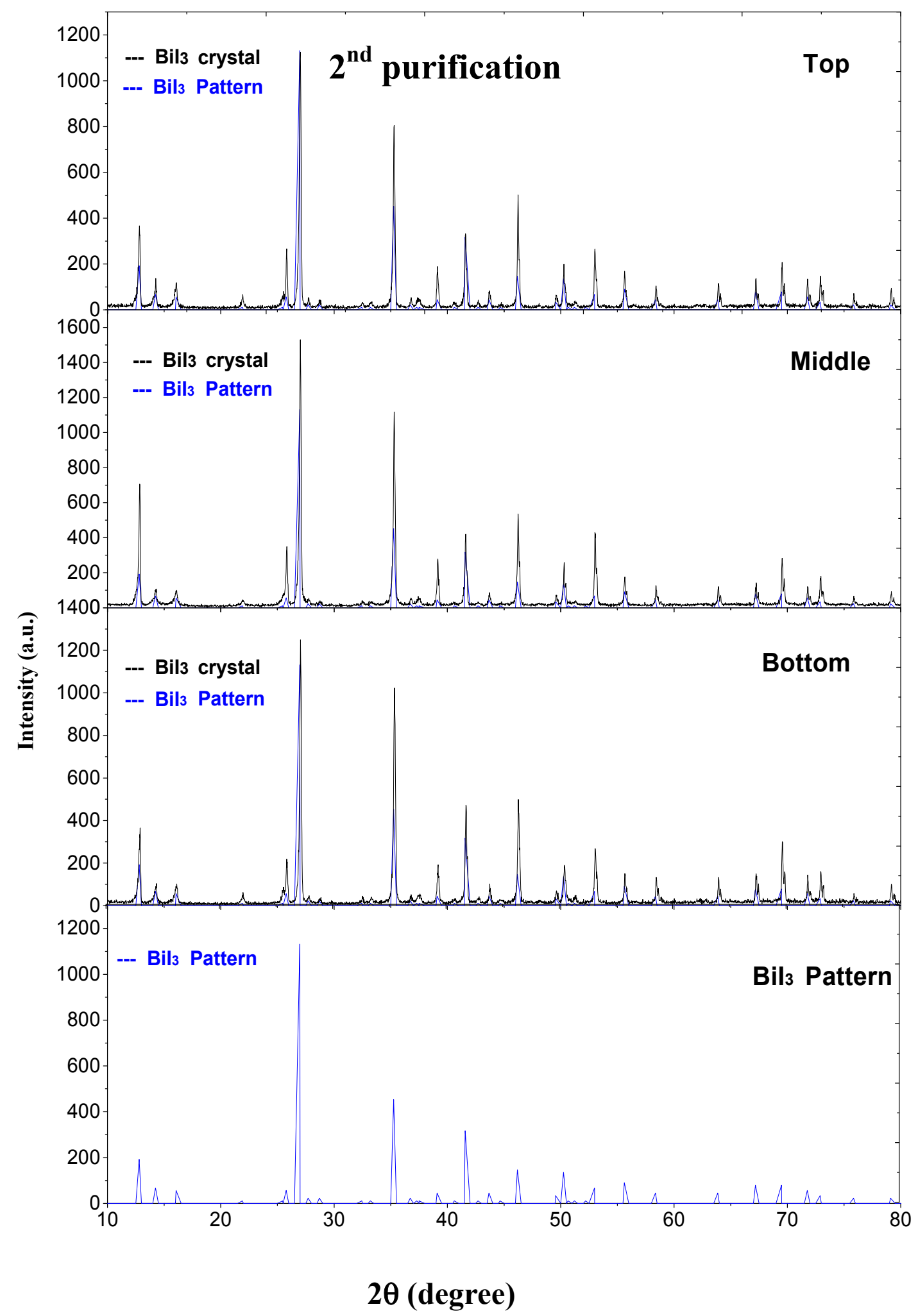

Figure 6. X-ray diffraction of the Top, Middle, Bottom samples from $\mathrm{BiI}_{3}$ crystal purified twice X-ray diffraction pattern of $\mathrm{BiI}_{3}$ (Card Information PDF Number: 48-1795) (Sillen, 1941). 


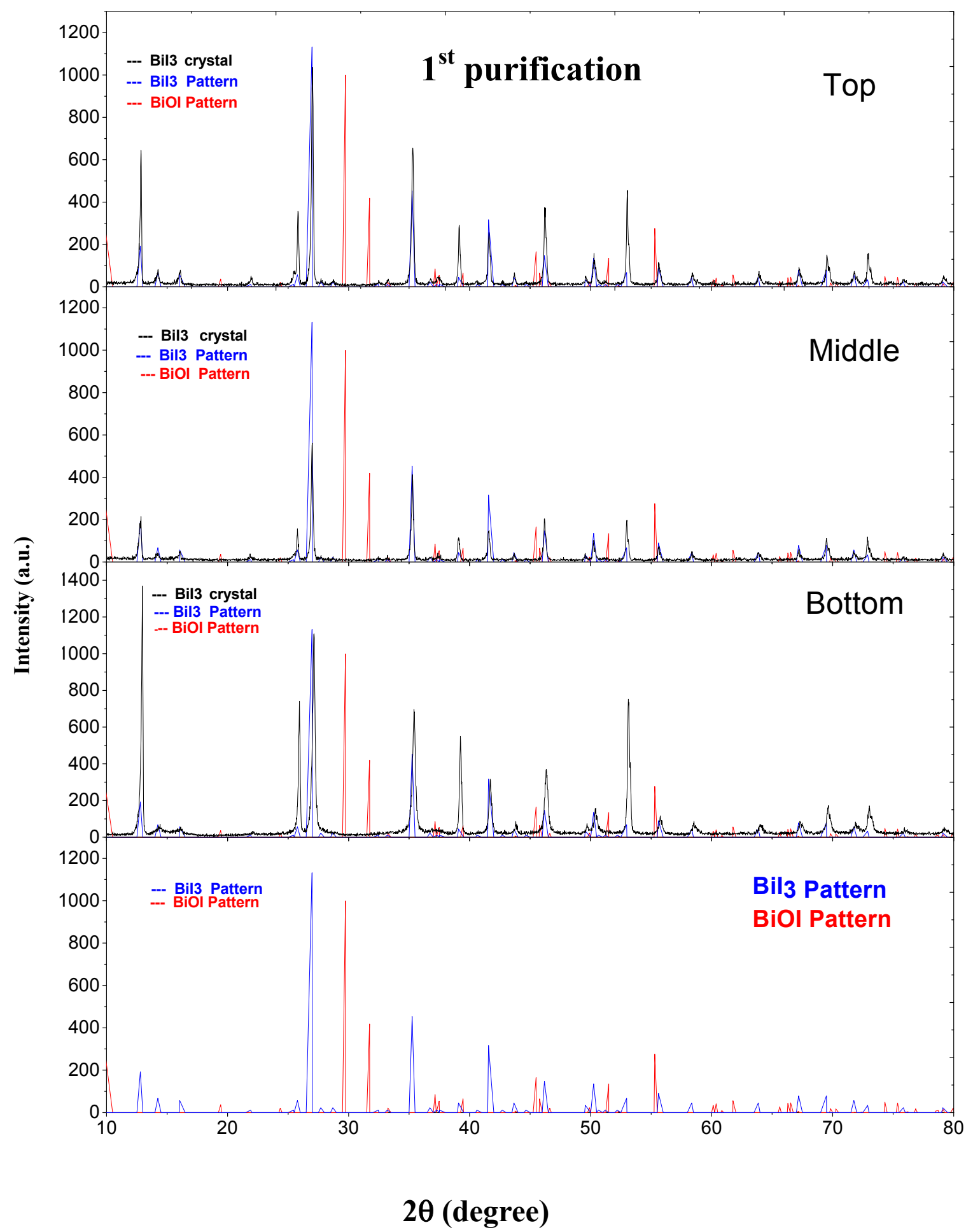

Figure 7. X-ray diffraction of the Top, Middle, Bottom samples from $\mathrm{BiI}_{3}$ crystal purified once X-ray diffraction pattern of $\mathrm{BiI}_{3}$ and $\mathrm{BiOI}$ (Card Information PDF number: 48-1795) (Sillen, 1941). 


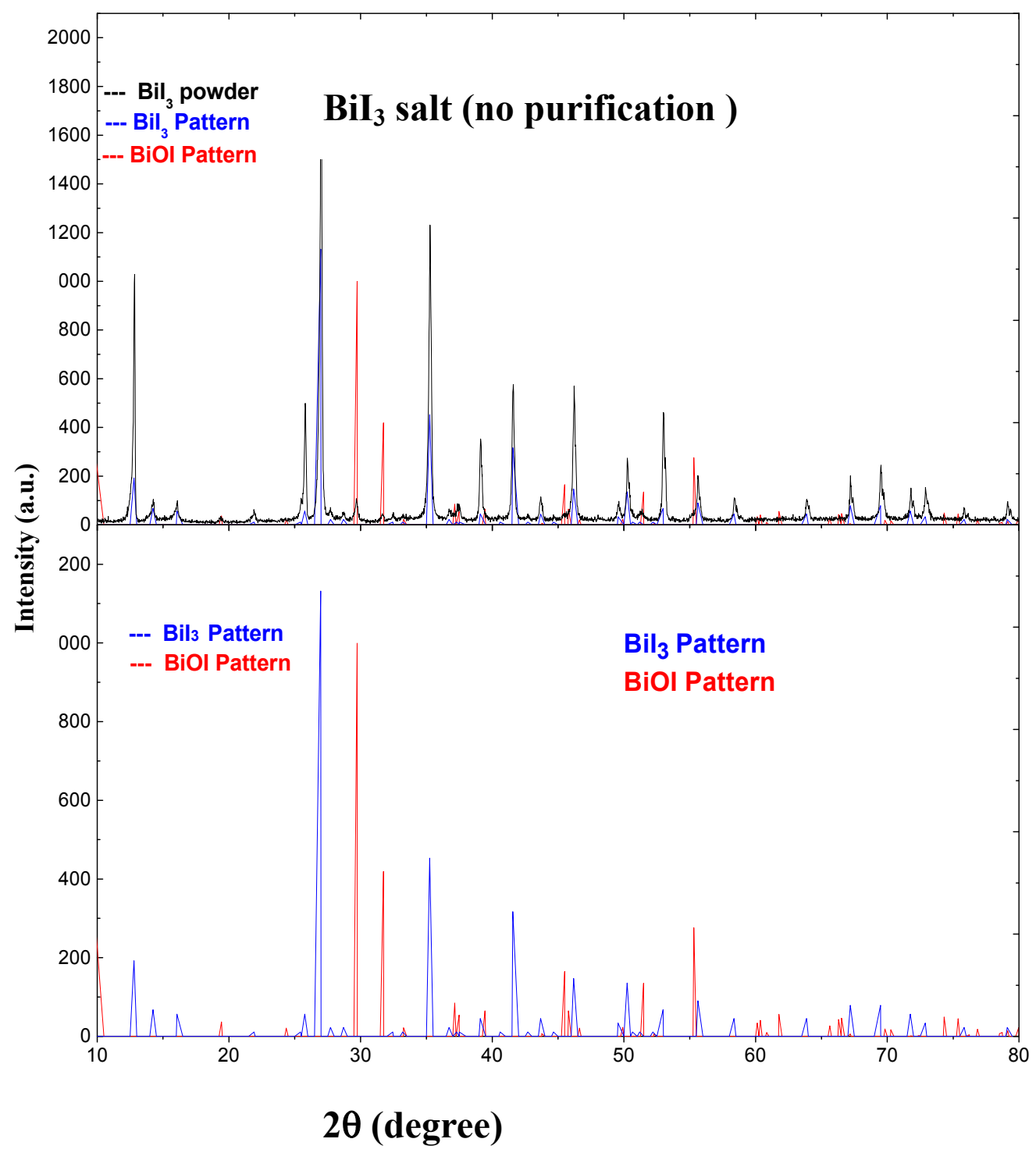

Figure 8. X-ray diffraction of $\mathrm{BiI}_{3}$ powder used.

X - ray diffraction pattern of $\mathrm{BiI}_{3}$ and BiOI (Card Information PDF Number: 48-1795) (Sillen, 1941)

A semi-quantitative scanning of the elements present on the crystal surface was performed using SEM-BSE technique, in order to evaluate the stoichiometry of $\mathrm{BiI}_{3}$. The elemental composition of the surface of the starting powder and crystal samples from each region (Top, Middle and Bottom) obtained by different purification numbers is shown in Table 3. The molar stoichiometric ratio of the crystal is practically 1 atom of $\mathrm{Bi}$ to 3 Iodine atoms, that is, $25 \%$ of the compound will be Bi and $75 \%$ of Iodine. 
Table 3. Elemental composition of crystal surface obtained by three purifications

\begin{tabular}{|c|c|c|c|c|}
\hline & Element & $\%$ Atomic & $\%$ Error & $\mathbf{I} / \mathbf{B i}$ \\
\hline Powder & $\mathrm{I}$ & 74.57 & 3.78 & 2,98 \\
\hline \multicolumn{5}{|c|}{$1^{\text {st }}$ Purification } \\
\hline & Element & $\%$ Atomic & $\%$ Error & $\mathbf{I} / \mathbf{B i}$ \\
\hline \multirow{2}{*}{ Bottom } & $\mathrm{I}$ & 70.22 & 4.06 & \multirow{2}{*}{2,36} \\
\hline & $\mathrm{Bi}$ & 29.78 & 8.12 & \\
\hline \multirow{2}{*}{ Middle } & $\mathrm{I}$ & 72.07 & 3.98 & \multirow{2}{*}{2,59} \\
\hline & $\mathrm{Bi}$ & 27.93 & 7.88 & \\
\hline \multirow{2}{*}{ Top } & $\mathrm{I}$ & 66.82 & 4.23 & \multirow{2}{*}{2,01} \\
\hline & $\mathrm{Bi}$ & 33,24 & 10.2 & \\
\hline \multicolumn{5}{|c|}{$2^{\text {nd }}$ Purification } \\
\hline \multirow{2}{*}{ Bottom } & $\mathrm{I}$ & 68.83 & 4.13 & \multirow{2}{*}{2,21} \\
\hline & $\mathrm{Bi}$ & 31.17 & 7.30 & \\
\hline \multirow{2}{*}{ Middle } & $\mathrm{I}$ & 72.67 & 3.87 & \multirow{2}{*}{2,66} \\
\hline & $\mathrm{Bi}$ & 27.33 & 8.62 & \\
\hline \multirow{2}{*}{ Top } & $\mathrm{I}$ & 66.34 & 4.60 & \multirow[t]{2}{*}{1,97} \\
\hline & $\mathrm{Bi}$ & 33.66 & 7.58 & \\
\hline \multicolumn{5}{|c|}{$3^{\text {rd }}$ Purification } \\
\hline \multirow{2}{*}{ Bottom } & $\mathrm{I}$ & 74.81 & 3.67 & \multirow{2}{*}{2,94} \\
\hline & $\mathrm{Bi}$ & 25.19 & 9.57 & \\
\hline \multirow{2}{*}{ Middle } & $\mathrm{I}$ & 75.85 & 3.62 & \multirow{2}{*}{3,1} \\
\hline & $\mathrm{Bi}$ & 24.15 & 8.57 & \\
\hline \multirow{2}{*}{ Top } & $\mathrm{I}$ & 61.06 & 4.98 & \multirow{2}{*}{1,56} \\
\hline & $\mathrm{Bi}$ & 38.94 & 5.73 & \\
\hline
\end{tabular}

As it can be seen from Table 3, a proper stoichiometry was found in the starting powder, at a very close value of 3: 1 (2.98: 1). However, in the first purification, a lower ratio was found compared to that present in the starting salt, with 2.59: 1 for the Middle region, that corresponds to $72.07 \%$ of I and $27.93 \%$, of Bi. For the Top and Bottom regions the findings were determined to be 2.01: 1 and 2.36: 1 . These results suggest that the impurities present in the salts used as starting material may interfere with the stoichiometry of the crystal, during its growth.

On the other hand, an improvement in the stoichiometric ratio was observed at each purification number, that is, the stoichiometry improved as a function of the reduction of impurities in the crystal. In the $3^{\text {rd }}$ purification, the stoichiometric ratio was very close to 3:1, being 3:1.1 in the Middle region and 2.94: 1 in the Bottom region, suggesting that the impurities migrated to the upper end of the crystal, i.e. in the end of the crystal growth, indicating that most trace elements, present as impurity, have $\mathrm{k}>1$.

Figure 8 shows the micrographs of the scanning electron microscopy with back-scattered electrons (SEM-BSE) carried out in Bottom, Middle and Top regions from the crystal surface obtained after first, second and third purification, in order to evaluate the quality of $\mathrm{BiI}_{3}$ wafer surface. 
$1^{\text {st }}$ purification
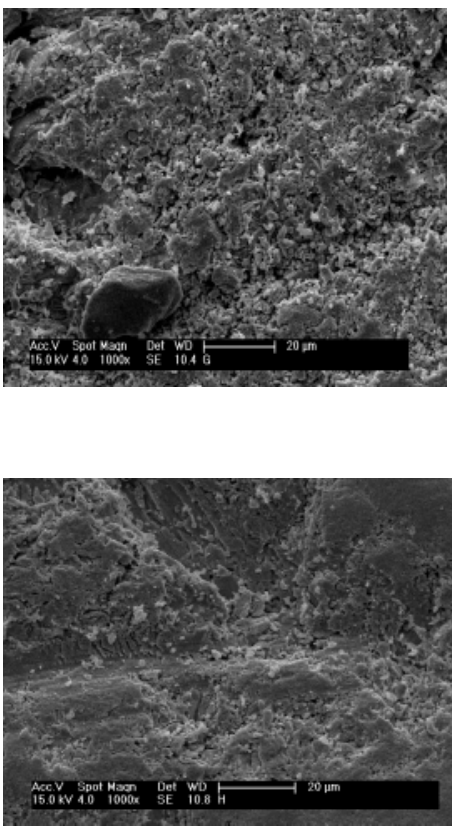

Middle

Bottom

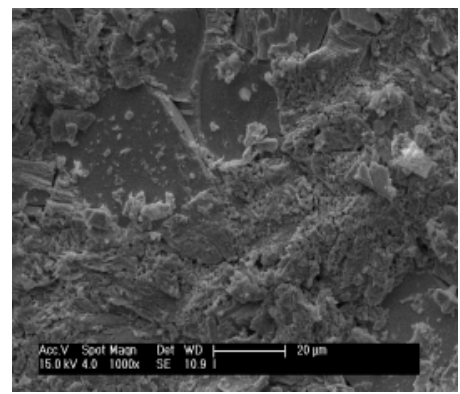

(A) $2^{\text {nd }}$ purification
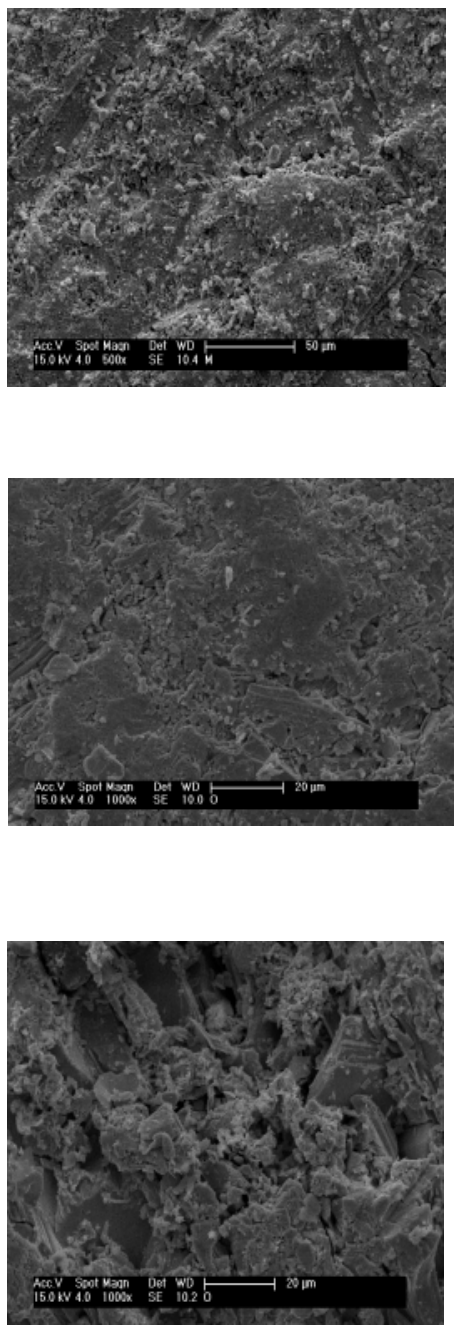

( B)

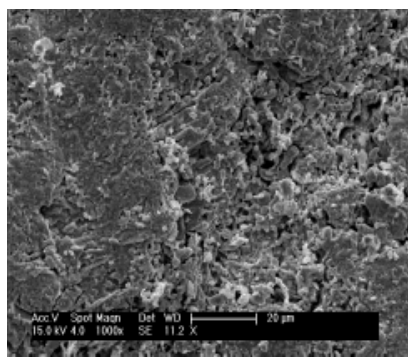

$3^{\text {rd }}$ purification
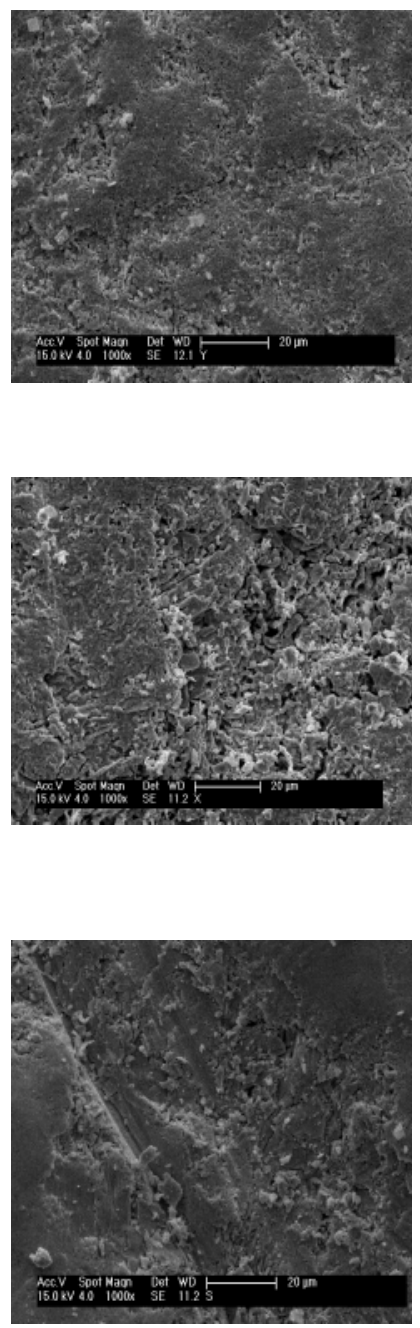

(C)

Figure 10. Micrographs of the $\mathrm{BiI}_{3}$ crystal surface purified once (A); twice (B) and third times (C) expanded 1000X

As it may be observed from Figure 8, for crystals purified once (Figure 8A), the Middle and Top regions present polycrystalline structures, while the Bottom region shows only an amorphous structure with roughness.. This may be due to the presence of impurities and/or defects in the surface of the crystal. For the crystal purified twice (Fig 8B), the Bottom region still presents an amorphous structure, while the Top region shows more crystals forming in its structure. In the Middle region, crystal structures may still be observed, but with impurities traces. These impurities present in the Middle region may have migrated from the Bottom region at a slower rate than the others present in the Top region, in other purifications, because their impurity segregation constant (k) is different. For crystal purified three times (Fig 8C), the Bottom and Top regions show amorphous structures due to the impurities present and which had not migrated in the previous purifications yet and the Middle region still presents more crystals forming, but the presence of impurities is not practically observed.

Validation of the methodologies for purification process and growth of the $\mathrm{BiI}_{3}$ by the Vertical Bridgman technique, as well as the establishment of a method for accompanying the reduction of the impurities, after each purification process are important for future works on the application this crystal as a room temperature radiation semiconductor detector. It is known that semiconductor detectors fabricated from high purity crystal exhibit significant improvement in their performance compared to those produced from low purity crystals. 


\section{Conclusion}

The Repeated Vertical Bridgman Method showed to be effective to reduce the concentration of many impurities in $\mathrm{BiI}_{3}$. After three purifications, most of the impurities, such as $\mathrm{Mn}, \mathrm{As}, \mathrm{Cr}$ and $\mathrm{Sb}$ were, practically, removed. Neutron Activation Analysis (NAA) showed to be a special technique to identify and quantify the impurities in the $\mathrm{BiI}_{3}$ crystals and to evaluate the reduction of the impurities. The segregation of most of the total impurities to the ends of the crystal indicates that the purification method established in this work was efficient. No other crystalline phase in the $\mathrm{BiI}_{3}$ purified twice and three times by Vertical Bridgman Method was found; all detected peaks were identified as belonging to $\mathrm{BiI}_{3}$. For crystal purified only once, an intensity contribution from Bismuth Oxide Iodide (BiOI) was observed. The sample from the Middle region of the $\mathrm{BiI}_{3}$ crystals, purified three times, presented a better result of stoichiometry evaluated by the analysis of MEV-BSE compared to that with less purification. By the analysis of SEM-SE, a crystalline structure was observed in the middle region of the crystals purified two and three times. The other regions showed an amorphous structure.

\section{Acknowledgements}

The authors express their acknowledgments to FAPESP-SP (grant: 12/05254-9) and CNPq (grant: 305210/2013-0) for the financial support. The authors C. M Ferraz and J. F. T. Martins thank the CNPq for the fellowship.

\section{References}

Alfassi, Z. B. (1998). Instrumental Multi-Element Chemical Analysis, Kluwer Academic Publishres: Dordrecht, the Netherlands. https://doi.org/10.1007/978-94-011-4952-5

Garg, A., Tomar, M., \& Gupta, V. (2014). Synthesis and Characterization of Thin Films of Bismuth Triiodide for Semiconductor Radiation Detectors, Conference Paper in Science, 2014. Article ID 370436, 3 pages, 2014, Hindawi Publishing Corporation. https://doi.org/10.1155/2014/370436

Gokhale, S. (2014) Bismuth tri-iodide radiation detector development. 2014 Thesis (Ph.D.) 140 pages - University of Florida, USA.

Gokhalea, S., Hanb, H., Baciaka, J. E., Ninob, J. C., \& Jordan, K. A. (2015). Growth, fabrication, and testing of bismuth tri-iodide semiconductor radiation detectors, Radiation Measurements, 74, 47-52. https://doi.org/10.1016/j.radmeas.2015.01.015

Hamada, M. M., Oliveira, I. B., Armelin, M. J., \& Mesquita, C. H. (2003). Trace impurities analysis determined by nêutron activation in the PbI2 crystal semiconductor, Nuclear Inst. And Methods in Physics Research, A, 505(1-2), 517-520.

Hitomi, K., \& Matsumoto, M. (2002). Thallium bromide optical and radiation detectors for X-ray and gamma-ray spectroscopy. IEEE Trans. Nuc. Sci., 49(5), 2526-2529. https://doi.org/10.1109/TNS.2002.803851

Keller, L., \& Nason, D. (1996). Powder Diffraction, 11, 91. https://doi.org/10.1017/S0885715600009040

Martins, J. F. T., Santos, R. A., Costa, F. E., Mesquita, C. H., \& Hamada M. M. (2012). Purification of HgI2 Crystals from Physical Vapor Transport for Application as Radiation Detectors. Advanced Materials Research (Online), 586, 156-160. https://doi.org/10.4028/www.scientific.net/AMR.586.156

Matsumoto, M., Hitomi, K., Shoji, T., \& Hiratate, Y. (2002). Bismuth Tri-Iodide Crystal for Nuclear Radiation Detectors", IEEE Transactions on Nuclear Science, 49(5), 2517-2519. https://doi.org/10.1109/TNS.2002.803883

McGregor, D. S., \& Hermon, H. (1997). Room-temperature compound semiconductor radiation detectors. Nucl. Instr and Meth. Phys. Res. A, 395, 101-124. https://doi.org/10.1016/S0168-9002(97)00620-7

Oliveira, I. B., Armelin, M. J. A., Costa, F. E., \& Hamada, M. M. (2002). Purification and Growth of $\mathrm{PbI}_{2}$ Crystals. Dependence of the Radiation Response on the $\mathrm{PbI}_{2}$ Crystal Purity. IEEE Transactions on Nuclear Science, 49(04), 1968-1973. https://doi.org/10.1109/TNS.2002.801483

Oliveira, I. B., Chubaci, J. F. D., \& Hamada, M. M. (2004). Purification and Preparation of TlBr Crystal for Room Temperature Radiation Detector Applications. IEEE Transactions on Nuclear Science, Estados Unidos, 51(03), 1224-1228. https://doi.org/10.1109/TNS.2004.829383

Pfann, W. G. (1958). Zone melting. John Wiley, New York, USA.

Qiu, W. A. (2010). Growth and Characterization of Bismuth Tri-iodide Single Crystals by Modified Vertical Bridgman Method. 2010 Thesis (Ph.D.)-University of Florida, USA.

Santos, R. A., Silva, J. B. R., Gennari, R. F., Martins, J. F. T., Ferraz, C. M., Hamada, C. M. M., \& Mesquita, C. H. (2012). Multi-elemental segregation analysis of thallium bromide impurities purified by the repeated Bridgman technique. Proceeding of Meeting in 2012 IEEE Nuclear Science Symposium and Medical Imaging Conference 
Record (NSS/MIC), 978, 4118-4123. https://doi.org/10.1109/NSSMIC.2012.6551941

Sillen, L. G., \& Sven, K. (1941). Tidskr, 53, 39.

Travesi, A. (1975). Analisis por activacion neutronica - teoria, práctica y aplicaciones, Ediciones J.E.N., Madrid.

\section{Copyrights}

Copyright for this article is retained by the author(s), with first publication rights granted to the journal.

This is an open-access article distributed under the terms and conditions of the Creative Commons Attribution license which permits unrestricted use, distribution, and reproduction in any medium, provided the original work is properly cited. 